\title{
(6) OPEN ACCESS \\ Rethinking eye health systems to achieve universal coverage: the role of research
}

\author{
Karl Blanchet, ${ }^{1}$ Clare Gilbert, ${ }^{1}$ Don de Savigny ${ }^{2,3}$
}

${ }^{1}$ Department of Clinical Research, International Centre for Eye Health, London School of Hygiene and Tropical Medicine, London, UK ${ }^{2}$ Swiss Tropical and Public Health Institute, London, UK ${ }^{3}$ University of Basel, Basel, Switzerland

\section{Correspondence to}

Dr Karl Blanchet, Department of Clinical Research,

International Centre for Eye Health, London School of Hygiene and Tropical Medicine, London WC1, UK;

karl.blanchet@lshtm.ac.uk

Received 26 June 2013 Revised 11 June 2014 Accepted 14 June 2014 Published Online First 2 July 2014
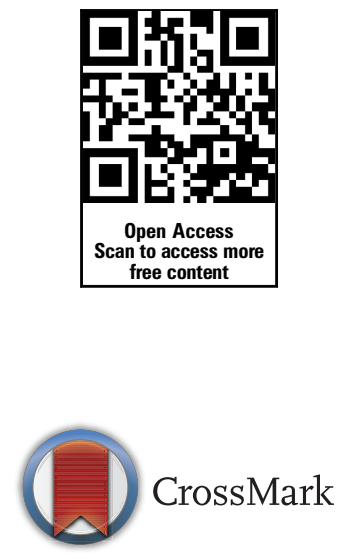

To cite: Blanchet $\mathrm{K}$, Gilbert C, de Savigny D. Br J Ophthalmol 2014;98:1325-1328.

\section{ABSTRACT}

Achieving universal coverage in eye care remains a tremendous challenge as 226 million people in the world remain visually impaired, the majority from avoidable causes. The impact of eye care interventions has been constrained by the limited capacities of health systems in low-income and middle-income countries to deliver effective eye care services. Services for eye health are still not adequately integrated into the health systems of low-income and middle-income countries. We contend that radical rethinking and deeper development of eye health systems are necessary to achieve VISION 2020 goals. Responding to the challenges of chronic eye diseases will require systems thinking, analysis and action, based on evidence from health systems research.

\section{INTRODUCTION}

The VISION 2020 global strategy for the elimination of avoidable blindness has created great momentum in the world of international eye health. Nevertheless, we are currently far from achieving universal health coverage for the 226 million people in the world, ${ }^{1}$ many of whose visual impairment could have been prevented or could be treated. ${ }^{2}$ It has been estimated that an additional \$5.8 dollars per person per year are needed between 2010 and 2020 to control avoidable blindness $^{3}$ with $48 \%$ of this investment being needed in low-income and middle-income countries (LMICs). ${ }^{3}$ But will this extra money yield the expected benefits? We argue that these investments will be inefficient if investors and implementers do not take into account the dynamics and complexities of local health systems and strengthen their capacities.

The WHO has defined a health system as 'all organizations, people and actions whose primary intent is to promote, restore or maintain health' $\left(^{4}\right.$ p. 1). In other words, a health system is seen as a system producing and organising goods (eg, infrastructure, equipment, drugs) and services (ie, health services) to achieve the objective of improving the health of the population. This definition has the advantage of being very comprehensive. It includes all non-health activities and actors (public and private sectors) that aim to have a direct or indirect impact on health (eg, new legislation on road traffic, improvement of education, pollution reduction strategies). Health systems should respond to the health needs in the community and be accessible without causing catastrophic out-of-pocket expenditure.

Defining a health system has become more challenging in a globalised world due to the multiplicity of actors intervening on different scales and the increasing interactions between global health policies and local health systems ${ }^{5}$ (see figure 1). Analysing health systems consists in understanding how they are structured and how the six building blocks of the system (ie, governance, human resources, finance, health information, consumables and technology and service delivery) function and inter-relate. ${ }^{6}$ Describing the specific elements of the health system allows a systematic approach to identifying limitations and where action is needed. However, it is acknowledged that each element should not be seen in isolation as they interact with each other. ${ }^{7}$ Every country has a unique health system characterised by the political climate and role of the government (eg, liberal, socialist; laissezfaire or interventionist) and the values they espouse (ie, more or less equitable), the model of financing (eg, taxes or private insurances) and its history. ${ }^{8}$

\section{THE CONSEQUENCES OF WEAK HEALTH SYSTEMS}

The environment in which health systems function has been influenced by the recent global financial crisis and Western public opinion refocusing their interests on national issues. However, the economies of many developing countries are expanding, and there is the potential for investment in health to meet the demands of a growing and ageing population. In this new funding landscape, synergies and efficiency become even more necessary in international eye health. ${ }^{10}$ International development also struggles to reduce poverty and inequality in the world, ${ }^{11}$ and the slow progress can partly be explained by inadequate resources being invested in health by developing countries and international donors. ${ }^{11-14}$ International aid, which has tended to focus on disease-specific interventions, ${ }^{15}$ has failed to reduce health inequalities between socioeconomic groups in developing countries $^{16} 17$ with barriers to effective delivery being attributed to the limited capacities of health systems in developing countries to sustain benefits for all categories of the population. ${ }^{18-27}$

At the start of the twenty-first century, developing countries face a double crisis: a devastating burden of disease $(90 \%$ of those with visual impairment live in LMICs), ${ }^{28}$ and inadequate health systems to deal with them. ${ }^{29}$ Where health systems fail to deliver quality and accessible eye care services $^{30}$ and do not raise awareness about eye disease and where to access services, people find other solutions that may create counter effects: (i) private clinics, which may force people to sell assets or forego other investment, such as education for their children; (ii) self-medication with substandard medicines purchased in the market or 


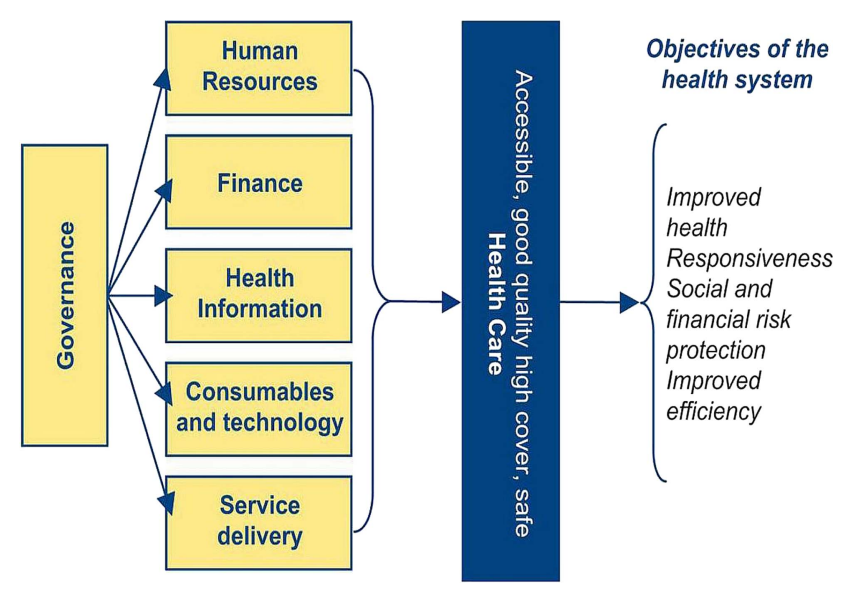

Figure 1 Different elements of the health system. ${ }^{9}$

from informal providers ${ }^{31}$ or (iii) traditional healers who may cause more harm than good. ${ }^{32}$ However, there is still limited evidence from eye health systems research.

\section{HEALTH SYSTEMS RESEARCH LIMITED IN EYE CARE}

In November 2012, in Beijing, the international community met at the second Global Symposium on Health Systems Research to discuss current innovations in health systems research, with a focus on universal coverage. However, the eye care community was surprisingly absent from this event. Despite the large body of evidence on barriers to accessing services (eg, for cataract and trichiasis surgery), ${ }^{30}{ }^{33-36}$ there is little research on how health systems can effectively respond in ways that are sustainable and effective: for example, an analysis of systematic reviews revealed absence of evidence on factors enabling or constraining universal coverage of cataract surgical services. ${ }^{37}$ The authors of this paper concluded that both primary research and systematic reviews were needed in eye care to identify the relationships between eye health systems and the effectiveness of eye care interventions.

The slow progress made in eye care on the diffusion of innovative system thinking may well reflect the disconnect between the eye care community with the rest of the health sector. Indeed, learning can be bi-directional: on the one hand, eye health professionals can learn from other health areas where applicable evidence may be available. ${ }^{38}$ On the other hand, evidence generated in eye health systems research can help answer pressing public health questions such as the impact of integration on access to services or the effectiveness of task shifting (eg, use of cataract surgeons).

A major challenge facing health systems in LMICs is the rapid emergence of non-communicable diseases, such as diabetes, hypertension and cardiovascular disease, ${ }^{39}$ which require a range of interventions for control, ranging from health promotion and regulation, mechanisms for early detection, predictive lifelong self-care and adherence to treatment, management of complications and long-term follow-up. ${ }^{39}$ This is in stark contrast to the once off or short-term interventions required for most infectious diseases (excluding trachoma and onchocerciasis) and for cataract and refractive error.

In this paper, we discuss ways in which eye health systems in LMICs might respond to existing challenges in eye care delivery, for example, how to increase cataract surgical rates, as well as the emerging challenges posed by non-communicable eye diseases. In most low-income countries, eye care at the primary level is almost non-existent, and one way to strengthen eye health systems is to integrate primary eye care into primary health care as a means of detecting and referring individuals with operable cataract, for example. Responding to noncommunicable eye diseases will have implications for the eye health workforce, health management information systems, equipment, consumables and supplies of medication, for example.

\section{HUMAN RESOURCES FOR HEALTH}

Human resources for health illustrates how responding to one issue requires exploration of other aspects of the health system. There is clear evidence that the number of eye care professionals is insufficient in many LMICs. ${ }^{40}{ }^{41} \mathrm{~A}$ recent study on human resources for eye health in 21 of the most populated countries in sub-Saharan showed that most countries (19 out of 21 countries) had fewer ophthalmologists than recommended (ie, four per million population), but the most striking finding was that, on average, almost $70 \%$ of ophthalmologists worked in the capital city. ${ }^{41-43}$ No country had the recommended number of optometrists, and cataract surgeons were the only cadre located primarily outside the capital. Increasing the number of cataract surgeons, and supporting them, is therefore a possible way of increasing the coverage of cataract surgical services in rural areas. At first sight, the solution seems obvious: train more eye care professionals. However, further analysis is needed in order to understand the characteristics of each health system: Can the labour market absorb the newly trained staff? Are there policies for the deployment and retention of staff? What are the pull and push factors that encourage internal and external migration and how can they be modified? If the market is not flexible enough to absorb new staff, how can task shifting help increase coverage of services? ${ }^{44-48}$ The recruitment of new staff may also require additional supervision and management, and standard equipment needs to be provided for new arrivals. This nonexhaustive list of questions shows how complex and multifaceted a health system response to one issue can be.

\section{INTEGRATION}

Due to the dearth of primary eye care in LMICs, most eye care delivery focuses on the provision of curative care at the secondary and tertiary levels of the health system. This leads to inequity in access, greater costs for patients and lack of effective interventions for prevention. ${ }^{49}$ One way to improve access to eye care and referral systems in LMIC is to integrate eye care into primary health care, but this raises passionate debates. ${ }^{50} 51$ Nevertheless, there is evidence that integration of eye care at the primary health level can be effective through enhanced supervi$\operatorname{sion}^{52}$ and training of primary health staff. ${ }^{53}$

\section{FLEXIBILITY AND INNOVATION}

As suggested by the new WHO eye health strategy, ${ }^{54}$ integration needs to be combined with health system strengthening, moving away from a disease-specific approach. Examples include management information systems that include eye care, as has been successfully achieved in Kenya ${ }^{55}$ and increasing the number, distribution, competencies and motivation of eye care personnel. The lack of health personnel globally (an estimated shortfall of 4.2 million) is receiving international attention, and evidence will be needed to advocate for inclusion of eye care personnel in government's plans for strengthening their health workforce. ${ }^{56}$ Greater financial resource will be also needed, through budgetary allocation by Ministries of Health, or through other financing schemes such as national insurance or performance- 
based financing. Indeed, some countries (eg, India or Ghana) already include cataract surgery and treatment of other eye conditions in their insurance schemes. ${ }^{57}$ Effective public-private partnerships are a means of providing affordable healthcare to vulnerable communities, as in India where the government's National Rural Health Mission pays private ophthalmologists to treat infants with retinopathy of prematurity, for example. ${ }^{9} 2758$ While the 2009-2013 WHO strategy promoted the inclusion of eye health in national health policies, much needs to be done during the next 5 years to effectively translate integration at the health service level. ${ }^{54}$ Innovation and flexibility will be needed at service delivery and policy levels, ${ }^{59}$ and advocacy for eye health must be included alongside other sectors if it is not to be overlooked. An example of health systems research that has had a great impact is training technicians in India to take and interpret retinal images to screen for retinopathy of prematurity. The technicians achieved very high levels of sensitivity and specificity, allowing 'task-shifting' whereby they screen for ROP, only referring infants for confirmatory diagnosis by an ophthalmologist when they detect 'referral warranted ROP'. The technicians visit multiple neonatal units every week, and the approach has been scaled up across the state of Karnataka and beyond. ${ }^{60}$

Health systems are complex and dynamic and involve a wide range of factors and variables that need to be understood collectively. ${ }^{46}$ Eye care, being a discreet package of interventions, can contribute to general understanding of how health systems function and behave. ${ }^{48} 61$

\section{SYSTEMS THINKING}

The emergence of health systems thinking presents an opportunity for reflection on how to improve eye care delivery at the horizon of 2020. This will require analysing how eye health systems function, how they connect with general health systems, how the stakeholders interact and the various possible paths to meeting population needs in a way that is equitable and responsive. ${ }^{48}$ Attention needs to be put on the dynamics of health systems in different contexts and identify possible pathways to achieve universal coverage, as demonstrated by the diversity and pluralism of service delivery models existing on every continent (eg, the need for private and public sectors, formal and informal sectors). ${ }^{5} 6263$

Health systems in most low-income countries were essentially born in the early part of the twentieth century, ${ }^{64}$ and they have generally evolved at a slower pace than the changing needs of the populations. ${ }^{29}$ 65-68 There is increasing disparity between the adaptive capacities of these health systems and the changing environment and healthcare needs in which they operate. ${ }^{25}$ Today, the healthcare situation in low-income countries has evolved into one that cannot be described as highly controlled, where the state is at the centre of the system. ${ }^{69}$ In the majority of these countries, eye care provision, rather than being officially restricted to the formal health market, is often increasingly pluralistic, meaning that a variety of models of eye care service delivery is supplied by a variety of actors, which often act in isolation. This reflects the weak capacities of the government to monitor the existing health regulations. ${ }^{66} 68$

\section{CONCLUSION}

Services for eye health are still not adequately integrated into the health systems and policies of LMICs. Ambitious goals have been set to eliminate avoidable blindness in the current decade. We contend that radical rethinking and deeper development of eye health systems are necessary to achieve these goals. At the global level, such reform could benefit from a general Global
Health Systems Fund that would respond to the needs of those with chronic debilitating disease and create the synergies to bring together professionals and communities on a common platform of work at local levels. Responding to the challenges of chronic eye diseases will require systems thinking, innovative and flexible solutions, based on evidence from health systems research and analysis.

Contributors $K B, C G$ and $D S$ developed the objectives and structure of the paper. KB drafted the article. CG and DS revised it critically. KG, CG and DS approved the final version of the paper for publication.

Competing interests The authors of the paper certify that they have no affiliations with or involvement in any organisation or entity with any financial interest (such as honoraria; educational grants; participation in speakers' bureaus; membership, employment, consultancies, stock ownership or other equity interest; and expert testimony or patent-licensing arrangements) or non-financial interest (such as personal or professional relationships, affiliations, knowledge or beliefs) in the subject matter or materials discussed in this manuscript.

Provenance and peer review Not commissioned; externally peer reviewed.

Open Access This is an Open Access article distributed in accordance with the Creative Commons Attribution Non Commercial (CC BY-NC 3.0) license, which permits others to distribute, remix, adapt, build upon this work non-commercially, and license their derivative works on different terms, provided the original work is properly cited and the use is non-commercial. See: http://creativecommons.org/ licenses/by-nc/3.0/

\section{REFERENCES}

1 World Health Organisation. Action plan for the prevention of avoidable blindness and visual impairment 2014-2019. Towards universal eye health: a global action plan 2014-2019. Geneva: World Health Assembly, 2013.

2 World Health Organisation. Visual impairment and blindness fact. 2012 [cited 2013 February 6th]. http://www.who.int/mediacentre/factsheets/fs282/en/index.html

3 Armstrong $\mathrm{KL}$, Jovic M, Vo-Phuoc JL, et al. The global cost of eliminating avoidable blindness. Indian J Ophthalmol 2012;60:475-80.

4 World Health Organisation. World Health Report 2000. Geneva: World Health Organisation, 2000

5 Bloom G, Edström J, Leach M, et al. Health in a Dynamic World. Brighton: STEPS Centre, 2007.

6 World Health Organisation. Strengthening health systems to improve health outcomes-WHO's framework for action. Geneva: World Health Organisation, 2006.

7 Mounier-Jack S, Griffiths UK, Closser S, et al. Measuring the health systems impact of disease control programmes: a critical reflection on the WHO building blocks framework. BMC Public Health 2014;14:278.

8 Black N, Gruen R. Understanding health services. Maidenhead: Open University, 2008.

9 Blanchet K, Patel D. Applying principles of health system strengthening to eye care. Indian J Ophthalmol 2012:60:470-4.

10 World Economic Forum. Sustainable health systems - Visions, strategies, critical uncertainties and scenarios. Geneva: World Economic Forum, 2013

11 Garrett L. Do No Harm: The Global Health Challenge. Foreign Affairs 2007:14-38.

12 Pieterse JN. My Paradigm or Yours?: Alternative Development, Postdevelopment, Reflexive Development. The Hague: Institute of Social Studies, 1996.

13 Simms C, Rowson M, Marcus R, et al. Do No Harm: The Human Impact of Economic and Health Policy Reforms. London: Zed Books, 2005.

14 Commission on Macroeconomics and Health. Macroeconomics and health: Investing in health for economic development. Geneva: World Health Organization, 2001.

15 Murray CJ, Frenk J, Evans T. The Global Campaign for the Health MDGs: challenges, opportunities, and the imperative of shared learning. Lancet 2007:370:1018-20.

16 Mackintosh M, Koivusalo M. Commercialization of Health Care. Basingstoke: Palgrave Macmillan, 2005.

17 O'Connel T. Plenary Session: advancing equity through UHC: are we getting there? Policy experiences on shifting towards equity as a principle in UHC. 2nd Global Symposium on Health Systems Research Beijing. China: UNICEF, 2012.

18 Berman P. Health sector reform: making health development sustainable. Health Policy 1995;32:13-28.

19 Gilson L, Mills A. Health sector reforms in sub-Saharan Africa: lessons of the last 10 years. Health Policy 1995:32:215-43.

20 Cassels A. Health sector reform: key issues in less developed countries. J Int Dev 1995:7:329-47.

21 Glassman A, Reich MR, Laserson K, et al. Political analysis of health reform in the Dominican Republic.[see comment]. Health Policy Plan 1999:14:115-26. 
22 Bossert T. Analyzing the decentralization of health systems in developing countries: decision space, innovation and performance. Soc Sci Med 1998;47:1513-27.

23 Ranson MK, Hanson K, Oliveira-Cruz V, et al. Constraints to expanding access to health interventions: an emprirical analysis and country typology. J Int Dev 2003:15:15-39.

24 Dodd R, Cassels A. Health, development and the Millennium Development Goals. Ann Trop Med Parasitol 2006;100:379-87.

25 Paina L, Peters DH. Understanding pathways for scaling up health services through the lens of complex adaptive systems. Health Policy Plan 2012;27:365-73.

26 Dybul M, Piot P, Frenk J. Reshaping Global Health. Hoover Institution, 2012.

27 Frenk J. Reinventing primary health care: the need for systems integration. Lancet 2009:374:170-3.

28 Bygbjerg IC. Double burden of noncommunicable and infectious diseases in developing countries. Science 2012;337:1499-501.

29 Bossert TJ. Health systems. Health Policy Plan 2012;27:8-10.

30 Goldschmidt $P$, Einterz $E$. The limits of medical interventions for the elimination of preventable blindness. Trop Med Health 2014;42:43-52.

31 Brieger WR, Osamor PE, Salami KK, et al. Interactions between patent medicine vendors and customers in urban and rural Nigeria. Health Policy Plan 2004; 19:177-82

32 Gilbert CE, Murthy GV, Sivasubramaniam S, et al. Couching in Nigeria: prevalence, risk factors and visual acuity outcomes. Ophthalmic Epidemiol 2010;17:269-75.

33 Abubakar T, Gudlavalleti MVS, Sivasubramaniam S, et al. Coverage of hospital-based cataract surgery and barriers to the uptake of surgery among cataract blind persons in Nigeria: The Nigeria National Blindness and Visual Impairment Survey. Ophthalmic Epidemiol 2011;19:58-66.

34 Finger R. Cataracts in India: current situation, access, and barriers to services over time. Ophthalmic Epidemiol 2007;14:112-18.

35 Gyasi MC, Amoaku WMK, Asamany DK. Barriers eye cataract surgical uptake in the Upper East Region of Ghana. Ghana Med J 2007;41:167-70.

36 Rajak SN, Habtamu E, Weiss HA, et al. Why do people not attend for treatment for trachomatous trichiasis in Ethiopia? A study of barriers to surgery. PLoS Negl Trop Dis 2012;6:e1766.

37 Blanchet K, Gordon I, Gilbert CE, et al. How to achieve universal coverage of cataract surgical services in developing countries: lessons from systematic reviews of other services. Ophthalmic Epidemiol 2012;19:329-39.

38 Blanchet K, Gordon I, Gilbert C, et al. How to Achieve Universal Coverage of Cataract Surgical Services in Developing Countries: Lessons from Systematic Reviews of Other Services. Ophthalmic Epidemiol 2012;9:329-39.

39 Atun R, Jaffar $\mathrm{S}$, Nishtar $\mathrm{S}$, et al. Improving responsiveness of health systems to non-communicable diseases. Lancet 2013:381:690-7.

40 Resnikoff S, Felch W, Gauthier TM, et al. The number of ophthalmologists in practice and training worldwide: a growing gap despite more than 200,000 practitioners. Br J Ophthalmol 2012;96:783-7.

41 Palmer J, Chinanayi F, Gilbert A, et al. Mapping Human Resources for Eye Health in Sub-Saharan Africa: Progress towards VISION 2020. London: IAPB, AVRI, ICEH London School of Hygiene and Tropical Medicine, 2013.

42 Palmer $\mathrm{P}$, Chinanayi F, Gilbert A, et al. Mapping human resources for eye health in 21 countries of sub-Saharan Africa: current progress towards VISION 2020. Human Ressources for Health, 2014; Under Review.

43 Palmer P, Chinanayi F, Gilbert A, et al. Trends and Implications for Achieving VISION 2020 Human Resources for Eye Health Targets in 16 Countries of Sub-Saharan Africa by Year 2020. Human Ressources for Health, 2014; Under Review.

44 Dovlo D. Health sector reform and deployment, training and motivation of resources toward equity in health care: issues and concerns in Ghana. Hum Reousrce Dev 2003;2.

45 Dovlo D. Wastage in the health workforce: some perspective from African countries. Hum Resour Health 2005:3.
46 de Savigny D, Kasale H, Mbuya C, et al. Fixing health systems. Ottawa: IDRC, 2004

47 Standing H. Gender-a missing dimension in human resource policy and planning for health reforms. Hum Resources Health Dev 2000;4:27-42.

48 Blanchet K, Gilbert C, Lindfield R. Eye health systems assessment (EHSA): How to connect eye care with the general health system. London: International Centre for Eye Health, London School of Hygiene and Tropical Medicine, 2012.

49 Woo GC, Woo SY. The need for full scope primary eye care in every country. Clin Exp Optom 2013;96:1-3.

50 Ackland P. The accomplishments of the global initiative VISION 2020: The Right to Sight and the focus for the next 8 years of the campaign. Indian J Ophthalmol 2012;60:380-6

51 du Toit R, Faal H, Etya'ale $D$, et al. Evidence for integrating eye health into primary health care in Africa: a health systems strengthening approach. BMC Health Serv Res 2013:13:102.

52 Okwen M, Lewallen S, Courtright P. Primary eye care skills scores for health workers in routine and enhanced supervision settings. Public Health 2014;128:96-100.

53 Ramke J, Blignault I, Hobday K, et al. Primary eye care in Timor-Leste. Br J Ophthalmol 2012;96:143-5.

54 World Health Organisation. Draft-Universal coverage to eye health: a global action plan, 2014-2019. Geneva: WHO, 2012.

55 Faal H, Cook C, Thulasiraj RD. Managing information in eye care programmes: the health systems perspective. Community Eye Health 2010;23:50-2.

56 Global Health Workforce Alliance. Making health workers count-Global Health Workforce Alliance-Annual Report 2012. Geneva: World Health Organisation, 2014.

57 Witter S, Garshong B. Something old or something new? Social health insurance in Ghana. BMC Int Health Hum Rights 2009;9:20.

58 Birla B, Taneja U. Public Private Partnerships for Healthcare Delivery in India. Internet J World Health Soc Politics 2008;7.

59 Peters DH, Rao KS, Fryatt R. Lumping and splitting: the health policy agenda in India. Health Policy Plan 2003;18:249-60.

60 Vinekar A, Gilbert C, Dogra M, et al. The KIDROP model of combining strategies for providing retinopathy of prematurity screening in underserved areas in India using wide-field imaging, tele-medicine, non-physician graders and smart phone reporting. Indian J Ophthalmol 2014;62:41-9.

61 Blanchet $K$, James $P$. Can international health programmes be sustained after the end of international funding: the case of eye care interventions in Ghana. BMC Health Serv Res 2014;14:77.

62 de Savigny D, Adam T. System thinking for health systems strengthening. Geneva: World Health Organisation, Alliance for Health Policy and Systems Research, 2009.

63 Patouillard E, Goodman CA, Hanson KG, et al. Can working with the private for-profit sector improve utilization of quality health services by the poor? A systematic review of the literature. International J Equity Health 2007:6:17.

64 Bloom G, Standing H. Future health systems: Why future? Why now? Soc Sci Med 2008:66:2067-75.

65 Bossert T, Beauvais JC. Decentralization of health systems in Ghana, Zambia, Uganda and the Philippines: a comparative analysis of decision space. Health Policy Plan 2002;17:14-31.

66 Larbi G. Implementing new public management reforms in Ghana: institutional constrainst and capacity issues — cases from public health and water services. Birmingham: University of Birmingham, 1998.

67 Sakyi EK. A retrospective content analysis of studies on factors constraining the implementation of health sector reform in Ghana. Int I Health Plann Manage 2008:23:259-85.

68 Peters DH, Muraleedharan VR. Regulating India's health services: to what end? What future? Soc Sci Med 2008:66:2133-44

69 Bloom G, Standing H. Pluralism and marketisation in the health sector: meeting health needs in contexts of social change in low and middle-income countries. Brighton: Institute of Development Studies, 2001 